Article

\title{
Treatment of Infection-Related Non-Unions with Bioactive Glass-A Promising Approach or Just Another Method of Dead Space Management?
}

\author{
Holger Freischmidt ${ }^{1,+}$, Jonas Armbruster ${ }^{1,+}{ }^{+}$, Catharina Rothhaas ${ }^{1}$, Nadine Titze ${ }^{1}$, Thorsten Guehring ${ }^{2}$, \\ Dennis Nurjadi ${ }^{3}{ }^{(D}$, Robert Sonntag ${ }^{4}\left(\mathbb{D}\right.$, Gerhard Schmidmaier ${ }^{5}$, Paul Alfred Grützner ${ }^{1}(\mathbb{D})$ and Lars Helbig ${ }^{5, *}$
}

check for

updates

Citation: Freischmidt, H.; Armbruster, J.; Rothhaas, C.; Titze, N.; Guehring, T.; Nurjadi, D.; Sonntag, R.; Schmidmaier, G.; Grützner, P.A.;

Helbig, L. Treatment of

Infection-Related Non-Unions with Bioactive Glass-A Promising Approach or Just Another Method of Dead Space Management? Materials 2022, 15, 1697. https://doi.org/ $10.3390 /$ ma15051697

Academic Editors: Isabel Gonzalo de Juan, Fabian Westhauser and Kunisch Elke

Received: 16 January 2022

Accepted: 22 February 2022

Published: 24 February 2022

Publisher's Note: MDPI stays neutral with regard to jurisdictional claims in published maps and institutional affiliations.

Copyright: (c) 2022 by the authors Licensee MDPI, Basel, Switzerland. This article is an open access article distributed under the terms and conditions of the Creative Commons Attribution (CC BY) license (https:// creativecommons.org/licenses/by/ $4.0 /)$.
1 Department of Trauma and Orthopedic Surgery, BG Trauma Center Ludwigshafen at Heidelberg University Hospital, 67071 Ludwigshafen am Rhein, Germany; holger.freischmidt@bgu-ludwigshafen.de (H.F.); jonas.armbruster@bgu-ludwigshafen.de (J.A.); catharina_97@gmx.de (C.R.); nadine.titze@gmx.de (N.T.); paul.gruetzner@bgu-ludwigshafen.de (P.A.G.)

2 Trauma Centre, Hospital Paulinenhilfe Stuttgart at Tübingen University Hospital, Rosenbergstr. 38, 70176 Stuttgart, Germany; thorsten.guehring@diak-stuttgart.de

3 Department of Infectious Diseases, Medical Microbiology and Hygiene, Heidelberg University Hospital, Im Neuenheimer Feld 324, 69120 Heidelberg, Germany; dennis.nurjadi@med.uni-heidelberg.de

4 Laboratory of Biomechanics and Implant Research, Clinic for Orthopedics and Trauma Surgery, Heidelberg University Hospital, Schlierbacher Landstrasse 200a, 69118 Heidelberg, Germany; robert.sonntag@med.uni-heidelberg.de

5 Clinic for Orthopedics and Trauma Surgery, Center for Orthopedics, Heidelberg University Hospital, Schlierbacher Landstrasse 200a, 69118 Heidelberg, Germany; gerhard.schmidmaier@med.uni-heidelberg.de

* Correspondence: lars.helbig@med.uni-heidelberg.de

+ These authors contributed equally to this work.

Abstract: The treatment of infected and non-infected non-unions remains a major challenge in trauma surgery. Due to the limited availability of autologous bone grafts and the need for local anti-infective treatment, bone substitutes have been the focus of tissue engineering for years. In this context, bioactive glasses are promising, especially regarding their anti-infective potential, which could reduce the need for local and systemic treatment with conventional antibiotics. The aim of this study was to investigate the osteoinductive and osteoconductive effects, as well as the anti-infectious potential, of S53P4 using a standardized non-union model, which had not been investigated previously. Using an already established sequential animal model in infected and non-infected rat femora, we were able to investigate bioactive glass S53P4 under realistic non-union conditions regarding its osteoinductive, osteoconductive and anti-infective potential with the use of $\mu \mathrm{CT}$ scans, biomechanical testing and histological, as well as microbiological, analysis. Although S53P4 did not lead to a stable union in the non-infected or the infected setting, $\mu \mathrm{CT}$ analysis revealed an osteoinductive effect of S53P4 under non-infected conditions, which was diminished under infected conditions. The osteoconductive effect of S53P4 remained almost negligible in histological analysis, even 8 weeks after treatment. Additionally, the expected anti-infective effect could not be demonstrated. Our data suggested that S53P4 should not be used in infected non-unions, especially in those with large bone defects.

Keywords: bioactive glass; animal model; non-union; bone defect; bone infection

\section{Introduction}

Treating non-unions has been an immense challenge for orthopedic surgeons for decades [1,2]. Although there has been plenty of research, and surgical interventions have gone through significant improvements, the physical suffering and psychological stress are still severe for patients [3,4]. Not to mention the socio-economical and financial implications they have on the health care system [5]. It is not surprising that non-union rates are widely dispersed in the literature since there are many risk factors, such as severity 
and location of the injury, age, nicotine abuse, diabetes or obesity [6]. Additionally, the type of therapy is of major interest for the outcome [7,8]. A femoral shaft fracture treated with an intramedullary nail has a $1.7 \%$ risk of developing a non-union [8], while a tibial fracture with a uniplanar external fixator has a non-union rate of $14 \%$ [9]. When it comes to open fractures and fracture infections, the healing process is even more complicated and often results in large bone defects [10]. The risk of infection after open fractures amounts to up to $50 \%$ [11], which is a major risk factor for non-healing. For example, in a Gustilo-Anderson Type III tibial shaft fracture, non-healing is found in $80 \%$ of cases [12].

Autologous bone grafts represent the current gold standard of non-union therapy [13]. It presupposes repeated surgical debridement, bone reconstruction and adequate stabilization, often with system antibiotics [14]. Autologous bone grafting requires an additional surgical intervention and it yields donor site morbidity [15]. Furthermore, it is limited in its quantity. Hence there is a need for bone graft substitutes with osteostimulative, osteoconductive and even perhaps with an antibiotic impact to have alternative, but equal, therapy options to autologous bone grafting [16]. Many approaches are being researched, including allograft or a demineralized bone matrix, cell-stimulating factors, as well as synthetic materials $[7,17,18]$. The main aim of a bone graft substitute is maintaining the space and stability of a scaffold while advancing bone healing [19].

Bioactive glasses, such as S53P4 (Bonalive Biomaterials Ltd., Turku, Finland), are bioactive materials that activate osteoblasts and, therefore, stimulate new bone formation by forming a silica gel layer with amorphous calcium phosphates on the glass surface, which crystalize to osteostimulative hydroxyapatite $[20,21]$. Furthermore, it potentially enhances angiogenesis [22-24]. In addition to serving as an osteoconductive scaffold, S53P4 is a promising possibility for treating bone defects [25-27]. Common approaches to gain an antibiotic effect are through loading carriers with antibiotics [28-30]. However, bioactive glasses show a different approach: the antibiotic effect is obtained through a rapid $\mathrm{pH}$ increase and a consequential osmotic effect [31-33]. This potentially qualifies them as a great alternative for treating osteomyelitis while avoiding drug resistance $[26,34]$. Several in vitro and in vivo studies exploring the spectrum of bioactive glasses have been conducted in the past $[19,22,26,35]$. However, the study populations and fractures were heterogenous and, thus, randomized, comparative, reliable and valid data were lacking.

Our group has previously established a sequential animal model for infection-related non-unions with segmental bone defects, which allowed the evaluation of therapeutic interventions in a genuine clinical simulation. [36]. To our knowledge, S53P4 has never been evaluated in a two-stage infectious non-union model. This study aimed to investigate the osteoinductive and osteoconductive effects, as well as the anti-infectious potential, of S53P4 using a standardized non-union model.

\section{Materials and Methods}

\subsection{Preparation of Infecting Agent}

Staphylococcus aureus subsp. aureus $\mathrm{ATCC}^{\circledR} 49230^{\mathrm{TM}}$ has already been established in several animal models $[36,37]$. The agent was cultured in a tryptic soy broth (TSB) at $37^{\circ} \mathrm{C}$ with $5 \% \mathrm{CO}_{2}$ under constant shaking (200 rpm). At mid-log phase on the day of infection the bacterial pellet was harvested, washed with sterile phosphate buffered saline (PBS), resuspended in sterile PBS and adjusted to $0.5 \mathrm{McFarland}$ standard $\left(1.5 \times 10^{8} \mathrm{CFU} / \mathrm{mL}\right)$. A concentration of $1 \times 10^{5} \mathrm{CFU} / \mathrm{mL}$ bacterial suspension was achieved by dilution, from which $10 \mu \mathrm{L}\left(=10^{3} \mathrm{CFU}\right)$ was used for the in vivo infection.

\subsection{Bioactive Glass (S53P4)}

The synthetic bone graft Bonalive ${ }^{\circledR}$ putty (Bonalive Biomaterials Ltd., Turku, Finland) is a bioactive glass S53P4 (53\% $\mathrm{SiO}_{2}, 23 \% \mathrm{Na}_{2} \mathrm{O}, 20 \% \mathrm{CaO}, 4 \%, \mathrm{P}_{2} \mathrm{O}_{5}$ [mass percentage/wt \%]), combined with polyethylene glycol and glycerine. It is provided as a paste, which can be used directly without any preparations. 


\subsection{Implants}

The first osteosynthesis was achieved with stainless steel Kirschner wires (Synthes $\mathrm{GmbH}$, Umkirch, Germany) with a diameter of $1.2-1.6 \mathrm{~mm}$, depending on the diameter of the femur. An angle-stable polyacetyl plate osteosynthesis with six cortical screws (RISystem AG, Davos, Cologny, Switzerland) was used for the second surgery.

\subsection{Groups}

We have included sixty-five animals in four groups (Table 1).

Table 1. The following groups were examined.

\begin{tabular}{|c|c|}
\hline Groups & Procedure \\
\hline $\begin{array}{l}\text { 1: NI control group (non-infected group, } \mathrm{n}=21 \text { ) } \\
\text { 2: I control group (infected control group, } \mathrm{n}=14 \text { ) }\end{array}$ & $\begin{array}{l}\text { K-wire osteosynthesis with intramedullary application of } 10 \mu \mathrm{L} \\
\text { PBS (non-infected) } / 10^{3} \mathrm{KBE} \text {. aureus in } 10 \mu \mathrm{L} \text { PBS (infected). } \\
\text { Debridement and re-osteosynthesis after } 5 \text { weeks with an } \\
\text { angle-stable plate. }\end{array}$ \\
\hline $\begin{array}{l}\text { 3: NI S53P4 (intervention group, non infected, } \mathrm{n}=16 \text { ) } \\
\text { 4: I S53P4 (intervention group, infected, } \mathrm{n}=14 \text { ) }\end{array}$ & $\begin{array}{l}\text { K-wire osteosynthesis with intramedullary application of } 10 \mu \mathrm{L} \\
\text { PBS (non-infected) } / 10^{3} \mathrm{KBE} \text {. aureus in } 10 \mu \mathrm{L} \text { PBS (infected). } \\
\text { Debridement and Re-osteosynthesis after } 5 \text { weeks with an } \\
\text { angle-stable plate and application of S53P4 to the bone defect. }\end{array}$ \\
\hline
\end{tabular}

\subsection{Animals, Operative Procedure and Osteotomy Model}

All experiments were approved by the Animal Experimentation Ethics Committee of the Regierungspräsidium Karlsruhe, Baden-Württemberg (35-9185.81/G-155/17). Sixty-five female, 3-month-old Sprague-Dawley rats (Charles River, Sulzfeld, Germany) were randomly divided into four groups, as described in Table 1.

The average weight was $285 \mathrm{~g}$. The animals were held in type IV macrolon cages under standard laboratory conditions $(12 \mathrm{~h}$-light-12h-dark cycles, room air temperature $22-24{ }^{\circ} \mathrm{C}$, humidity $50-60 \%$ ) in groups of 3-4 rats per cage. Access to water and food pellets was available ad libidum. There was a 2-week acclimatization period after arrival of the animals, before the first surgery took place.

A two-stage animal non-union model, previously established by our group [36], was used for this study. At first, an osteotomy was created and treated with K-wire osteosynthesis. Five weeks later, a second procedure was performed to switch to an anglestable plate osteosynthesis to treat the developed non-unions. Surgery was performed under general anesthesia by weight-adapted subcutaneous injection of medetomidine (Dorbene Vet $1 \mathrm{mg} / \mathrm{mL}$; Pfizer Deutschland GmbH, Berlin, Germany), midazolam (Midazolam HEXAL $5 \mathrm{mg} / \mathrm{mL}$; al AG, Holzkirchen, Germany) and fentanyl (Fentadon Dechra $50 \mu \mathrm{g} / \mathrm{mL}$; Dechra Veterinary Products Deutschland GmbH, Aulendorf, Germany). To prepare for surgery, the left hind leg was shaved and disinfected with alcohol. The animals were placed on drapes on a heating plate to hold their body temperature. The bodies were covered with sterile sheets. After blunt preparation throughout the skin and muscles, the femur was exposed and a $5 \mathrm{~mm}$ mid-diaphyseal full-thickness osteotomy was performed using a diamond disk (Dremel, Racine, WI, USA). Stainless steel K-wire with a diameter in the range 1.2-1.6 mm (Synthes, GmbH, Umkirch, Germany) was used to treat the defect with an intentionally rotational unstable osteosynthesis. Before applying the K-wire, $10 \mu \mathrm{L}$ PBS was added to the medullary cavity in groups 1 and 3 , and $10^{3}$ CFU S. aureus in $10 \mu \mathrm{L}$ PBS in infected groups 2 and 4. Skin, fascia and muscles were sutured using an intracutaneous technique (Resolon ${ }^{\circledR}$ 4/0 Ethicon, Norderstedt, Germany) and additionally adapted with skin clamps (Autoclip Clips, Heidelberg, Germany).

All animals received a second surgery five weeks after the first procedure. Surgical access was the same as previously described. After removing the K-wire a radical debridement was performed. Microbiological swabs and small tissue samples from the non-union were taken for further analysis. An angle-stable poly-acetyl plate $(25 \mathrm{~mm}$-long, $4 \mathrm{~mm}$-wide, RISystem AG, Davos, Switzerland) with eight predrilled holes for angle-stable cortical 
screws was situated on the anterolateral surface of the femur. Three screws, proximal and distal to the osteotomy were each used to fix the plate through the predrilled holes, so a stable plate osteosynthesis with an approximately $5 \mathrm{~mm}$ defect was created. Soft tissue was dried and S53P4 was modulated to fill the gap. The suture was made analogical to the first procedure.

\subsection{Follow-Up}

Buprenorphine $\left(0.3 \mathrm{mg} / \mathrm{mL}\right.$ bw; Buprenovet ${ }^{\circledR}$; Bayer AG, Leverkusen, Germany) was used as an analgesic medication perioperatively, as well as for the following four days every twelve hours. Body weight and body temperature, along with clinical conditions of the animals, were evaluated regularly. All animals were monitored for eight weeks after the second surgery and sacrificed.

\section{7. $\mu \mathrm{CT}$ Scan Evaluation}

$\mu \mathrm{CT}$ scans were performed with a Skyscan 1076 in vivo Micro-CT (Bruker, Kontich, Belgium), as previously described [38]. All animals had four scans in total. The first one was taken right before the second surgery to verify a non-union. After four and eight weeks, in vivo scans were performed for follow-up of the bone morphology. Immediately after sacrificing and removing the soft tissue, an ex vivo scan was performed to achieve a high-resolution image at the endpoint. The objects were scanned with a scan orbit of 360 degrees, an isotropic pixel size of $18 \mu \mathrm{m}$ and energy settings of $100 \mathrm{kV}$ (voltage), $280 \mathrm{~ms}$ (exposure time) and $100 \mu \mathrm{A}$ (current) through a $1.0-\mathrm{mm}$ aluminum filter. Rotation steps $\left(1^{\circ} / 0.6^{\circ} / 0.4^{\circ}\right)$ and frame averaging $(2 / 4 / 6)$ were adjusted regarding the different types of scans (pre-op scan/4- and 8-week in vivo scan/ 8-week ex vivo scan). Image reconstruction was performed by using SkyScan NRecon software (v.1.6.9.8, Bruker microCT, Kontich, Belgium): ring artefact reduction $(9 / 20)$, beam hardening correction (30\%) and smoothing $(1 / 10)$ were used as parameter settings. The contrast limits were set at $0-0.035$ pre-op and for the ex vivo scan and $0-0.3$ for the in vivo scans.

Two different scores by two independent observers each were assessed for qualitative evaluation of the datasets by simultaneously viewing a coronal, sagittal and transversal section in the SkyScan DataViewer (v.1.5.2.4, Brucker microCT, Kontich, Belgium).

The Lane and Sandhu scoring system was used to evaluate new bone formation, as previously described [39]. The modified An and Friedman Score was adapted to gauge the bone infection $[37,40]$.

A SkyScan CTAnalyzer (v.1.13.21, Brucker microCT, Kontich, Belgium) was used to quantitatively evaluate the bone adjacent to the defect gap. To define the volume of interest (VOI), the center of the defect gap was determined visually and locations $3 \mathrm{~mm}$ proximal and distal from there were selected, which gave a total bone area of $6 \mathrm{~mm}$ with 351 images per scan. The transversal extension of the VOI, the region of interest (ROI), was specified by drawing semi-manually: a ROI was drawn manually every 10 to 15 images and the intervening images were interpolated, checked manually afterwards and adapted if necessary. Whilst the control group was left empty in the defect group (control group: VOI_control; intervention group: VOI_bone), the intervention group had two additional VOIs per scan: by interpolating between two ROIs from the bone ends, a second ROI was created, which contained S53P4 and represented the maximum width of the bone (VOI_all). After subtracting VOI_bone and VOI_all, the third VOI, including only S53P4 and soft tissue, was generated.

The following parameters were used for bone morphometry of the VOI for each in vivo scan ( 4 and 8 weeks after the second surgery): bone volume, bone surface, bone surface volume ratio, bone surface density, trabecular thickness and total porosity.

Density measurements were derived from the ex vivo scans. Two Phantoms with known density $\left(0.25\right.$ and $\left.0.75 \mathrm{~g} / \mathrm{cm}^{3}\right)$ were used to calibrate the gray values of the CTAnalyzer and measurement of bone mineral density (BMD) and tissue mineral density (TMD) was performed: TMD, which is equivalent to cortical bone, was measured by thresholding 
VOI_bone; BMD, which represents trabecular bone and bone marrow, was measured by analyzing the ROI of S53P4.

\subsection{Microbiological Evaluation}

As previously described, microbiological samples were taken with a $10 \mathrm{~mL}$ wound $\mathrm{eSwab}^{\mathrm{TM}}$ (Becton Dickinson, Heidelberg, Germany) during the second surgery, as well as the sacrifice. A volume of $10 \mu \mathrm{L}$ of the sample was inoculated onto Columbia agar supplemented with 5\% sheep blood (Becton Dickinson, Heidelberg, Germany) and was cultured at $37{ }^{\circ} \mathrm{C}$ with $5 \% \mathrm{CO}_{2}$ for $24 \mathrm{~h}$ on BD Columbia agar. Colonies consistent with Staphylococcus aureus morphology were confirmed as $S$. aureus by the slide agglutination test (Pastorex Staph Plus, Bio-rad, Germany) [41] and MALDI-TOF (Bruker GmbH, Germany). Spa typing (comparison of the polymorphic protein A gene) by Sanger sequencing was performed to confirm the strain identity with the infection strain [41].

\subsection{Sacrifice}

All animals were sacrificed eight weeks after the second surgery under general anaesthesia followed by $\mathrm{CO}_{2}$ in a sedation box. Following an in vivo $\mu \mathrm{CT}$ scan, the left femora were approached as described in the preceding surgeries. After a microbiological swab was acquired from the osteotomy, proceeding under unsterile conditions was possible. The left femur was disarticulated at both joints and the soft tissue was detached from the bone. For all animals determined to undergo biomechanical testing, the right femora were also dissected. All operated femora had an ex vivo $\mu \mathrm{CT}$ scan. Afterwards, the bones assigned for biomechanical evaluation were stored at $-20{ }^{\circ} \mathrm{C}$ and the bones intended for histological evaluation were fixated in $4.5 \%$ paraformaldehyde (Roti-Histofix, Roth, Karlsruhe, Germany).

\subsection{Mechanical Testing}

The femora were biomechanically evaluated in a test device that measures the torsional stiffness of bones, as previously described [38]. The frozen femora were left for at least two hours at room temperature in saline solution to defrost. The plate osteosynthesis was removed. The distal and proximal parts of the bones were placed into two embedding molds (Technovit 4071, Heraeus Kulzer GmbH, Germany), while the defect region remained free for torsional testing. The lower embedding mold was connected to a pivotable axis, while rotation of the upper mold was restrained. The resulting maximum torque was recorded (8661-4500-V0200, Burster, Germany), while a linear constant rotation $\left(20^{\circ} / \mathrm{min}\right)$ was applied by the testing device until a fracture occurred. In the case of a stable decrease, or reaching a maximum torque of $0.5 \mathrm{Nm}$, the recording was stopped. For comparison, all contralateral femora were tested as well.

\subsection{Histology}

After sacrifice, the femora were fixated in $4.5 \%$ paraformaldehyde (Roti-Histofix, Roth, Karlsruhe, Germany) for four days and were decalcified with ethylenediaminetetraacetic (Entkalker Soft, Roth, Karlsruhe, Germany) for 3 weeks. Plates and screws were removed and a graded alcohol series was made for bone dehydration (2 days, $70 \%$ ethanol; 2 days, 96\% ethanol; 2 days, 100\% ethanol). The bones were placed in acetone for $8 \mathrm{~h}$ to degrease and embedded in paraffin afterwards. The paraffin block was cut at $5 \mu \mathrm{m}$ intervals at the longitudinal section of the bone down to the center of the sample. Sections were stained with haematoxylin and eosin (HE) (Carl Roth GmbH \& Co KG, Karlsruhe, Germany) and brilliant-crocein-fuchsin acid, and safran (Pentachrom: Chroma-Waldeck $\mathrm{GmbH} \& \mathrm{Co}$. KG, Münster, Germany) for overview staining. Furthermore tartrat-resistent acid phosphatase (TRAP) staining (Merck KGaA, Darmstadt, Germany) and Toluidine blue staining (Sigma-Aldrich Chemie $\mathrm{GmbH}$, Steinheim, Germany) were performed. In addition, immunohistochemical staining was performed with anti-CD14 (ab203294, Abcam, 
Cambridge, UK), anti-CD31 (ab182981, Abcam, Cambridge, UK) and anti-CD68 antibodies (ab125212, Abcam, Cambridge, UK).

All samples were provided by the Tissue Bank of the National Center for Tumor Diseases (NCT) Heidelberg, Germany, in accordance with the regulations of the tissue bank and the approval of the ethics committee of Heidelberg University. Fiji ImageJ (v.1.53c) was used for analysis. A $6 \mathrm{~mm}$ ROI, equivalent to the CT-VOI, was selected. The background was subtracted to minimize artefacts and a specific color threshold for each staining was applied (Table 2). The selected area, as well as the total bone area (hue $0 / 255$, saturation $0 / 255$, brightness $0 / 250$ ), was measured.

Table 2. Specific color threshold for each staining.

\begin{tabular}{cccc}
\hline & Hue & Saturation & Brightness \\
\hline CD31 & $200 / 255$ & $40 / 255$ & $0 / 255$ \\
\hline CD14 & $200 / 255$ & $60 / 255$ & $0 / 255$ \\
\hline CD68 & $200 / 255$ & $100 / 255$ & $0 / 255$ \\
\hline TRAP & $200 / 255$ & $90 / 255$ & $0 / 255$ \\
\hline
\end{tabular}

\subsection{Statistical Analysis}

Data were recorded in Excel (Microsoft, Redmond, WA, USA) and statistically analyzed via GraphPad Prism version 9.1.0 (GraphPad Software, San Diego, CA, USA). The D'Agosino-Pearson test was employed to evaluate for normal distribution. To test for the statistical significance of differences between the four groups, one-way analysis of variance (ANOVA) followed by Tukey's multiple comparisons test were performed. The $\mu \mathrm{CT}$ data at the two time points (four weeks and eight weeks postoperative) were compared using the Student's paired $t$-test. $p$-values $<0.05$ were considered statistically significant. All tests were performed two-sided. Data were presented as mean \pm standard deviation (SD) in the figures and throughout the manuscript unless otherwise indicated.

\section{Results}

\subsection{Failure Parameters}

Two rats died in the NI control group during anesthesia during the first intervention. Four rats of the NI S53P4 and one rat of the I S53P4 group died during the second intervention. One animal in the I S53P4 group had to be euthanized due to unconscionable wound conditions. Fifty-seven of the sixty-five animals reached the endpoint of the study.

Six animals from the NI control group and five animals from the NI S53P4 group had to be excluded due to a secondary bone infection. As previously described, a secondary bone infection was determined by a positive microbiological result and an An and Friedman score $\geq 19$ [36]. Positive microbiological results with an An and Friedman Score $<19$ were considered as colonization.

Additionally, 3 CT scans in the 4-week I control group and 1 CT scan in the 8-week I control group were excluded due to technical errors during the imaging process.

\subsection{Microbiologic Results Showed No Anti-Infective Potential in S53P4}

Microbiologic analysis at two time points (second surgery and euthanasia) showed more sterile results in the non-infected groups but some colonization and secondary infection with S. aureus. All bacteria detected in the non-infected groups had a different spa-typing than the inoculated strain. Infected groups showed the expected infection with the inoculated S. aureus strain. No clear pattern, leading to more sterile results in the S53P4 groups, could be detected. Furthermore, the infected S53P4 group showed even more variety in bacterial load with the detection of Enterobacterales (Enba) (Figure 1). 
Non-infected

\section{Control $2^{\text {nd }}$ Surgery}

Control Euthanasia

\section{S53P4} $2^{\text {nd }}$ Surgery

\section{S53P4}

Euthanasia



Total $=19$

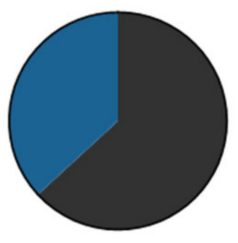

Total=19

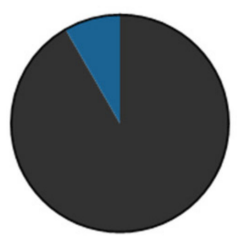

Total $=12$

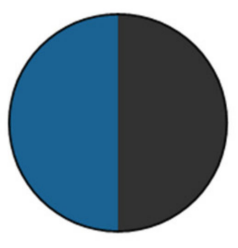

Total $=12$

\section{Infected}



Total $=14$

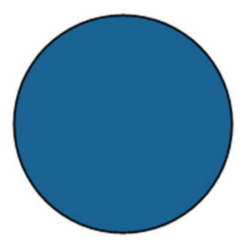

Total=14

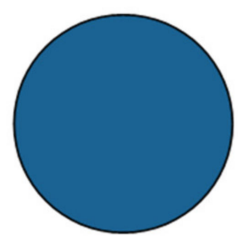

Total $=12$

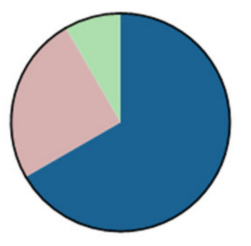

Total=12
14 - S. aureus

14 - S. aureus

12 - S. aureus
8 - S. aureus

- 3 - Enba

$\square 1$ - S. aureus + Enba

Figure 1. Microbiologic results of all animals after second surgery and euthanasia. Rats with secondary infection and colonization are both displayed as part of the S. aureus group. Abbreviations: Enba $=$ Enterobacterales.

\subsection{S53P4 Did Not Lead to a Stable Union in Non-Infected or Infected Conditions}

Biomechanical testing of the femora was performed by measuring the maximum torque. In all the measured groups, the maximum torque was significantly lower than in the contralateral femora (CF NI control, $0.45 \mathrm{Nm}$ ) (Figure 2). No significant difference was detected in the ipsilateral femora between the control and S53P4 groups, regardless of the treatment in non-infected or infected conditions (Figure 2); thus, S53P4 alone did not lead to functionally relevant stability of the bone.

3.4. $\mu \mathrm{CT}$ Analysis of the Bone Showed an Osteoinductive Effect of S53P4 in Non-Infected Groups, Which Was Diminished in Infected Groups

$\mu \mathrm{CT}$ analysis of the bone 4 and 8 weeks after the second surgery revealed an osteoinductive effect of S53P4 in non-infected conditions (Figure 3A) with a significant increase in bone volume and a decrease in porosity. This effect was already detectable at the 4-week timepoint but was even more apparent at the 8-week timepoint. Under infected conditions, S53P4 also showed an osteoinductive effect, which could not reach the potential in the non-infected groups (Figure 3A). 


\section{Mechanical Testing}

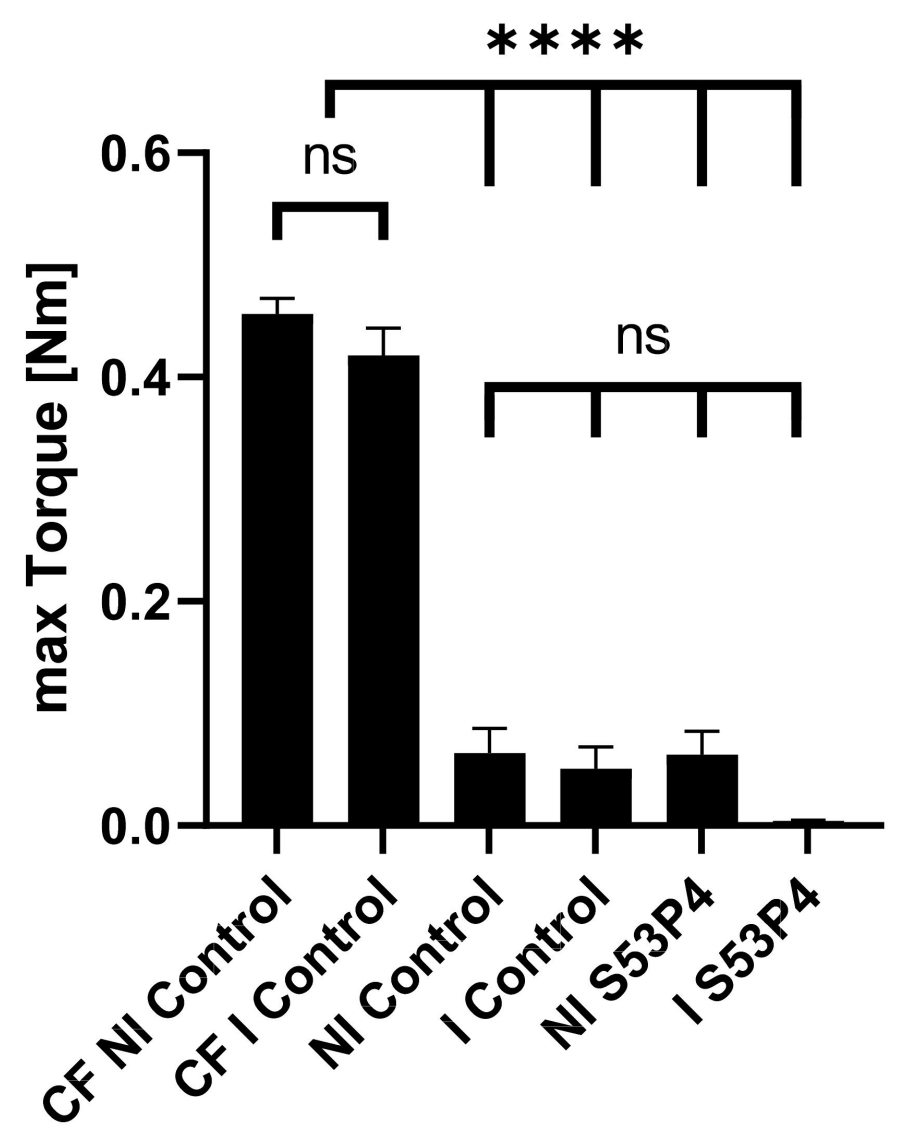

Figure 2. Mechanical testing. Max. torque of the non-infected contralateral femora (CF NI control) was significantly higher than the max. torque of all other groups. No significant differences between non-infected (NI) and infected (I) groups or the control and S53P4 groups were detected. $* * * *=p<0.0001 ; \mathrm{ns}=$ not significant.

The density of the bone and the bone graft S53P4 was measured via density analysis during the CT scans in the segmented regions corresponding to bone tissue following the tissue mineral density (TMD) protocol of the analysis software. The bone density was significantly lower in infected groups than in the non-infected counterparts. No significant difference was seen between the control and S53P4 groups (Figure 4a). S53P4 density measurements (bone mineral density-BMD) showed a significant decrease in the infected samples (Figure 4b).

\section{5. $\mu \mathrm{CT}$ Analysis of S53P4 Showed the Detrimental Effects of Infection}

$\mu \mathrm{CT}$ analysis of S53P4 4 and 8 weeks after the second surgery showed a significant decrease in the bone graft volume just 4 weeks after the surgery, which further decreased significantly until 8 weeks postoperation. In contrast, the bone graft volume in the noninfected group even increased between 4 and 8 weeks leading to an even further gap between those two groups (Figure 5). Correspondingly, the surface volume ratio increased in I S53P4 while the surface density decreased. Lastly, the porosity rose to nearly 100\%, indicating that the S53P4 was almost gone at that point (Figure 5). 
A



Figure 3. Cont. 
B

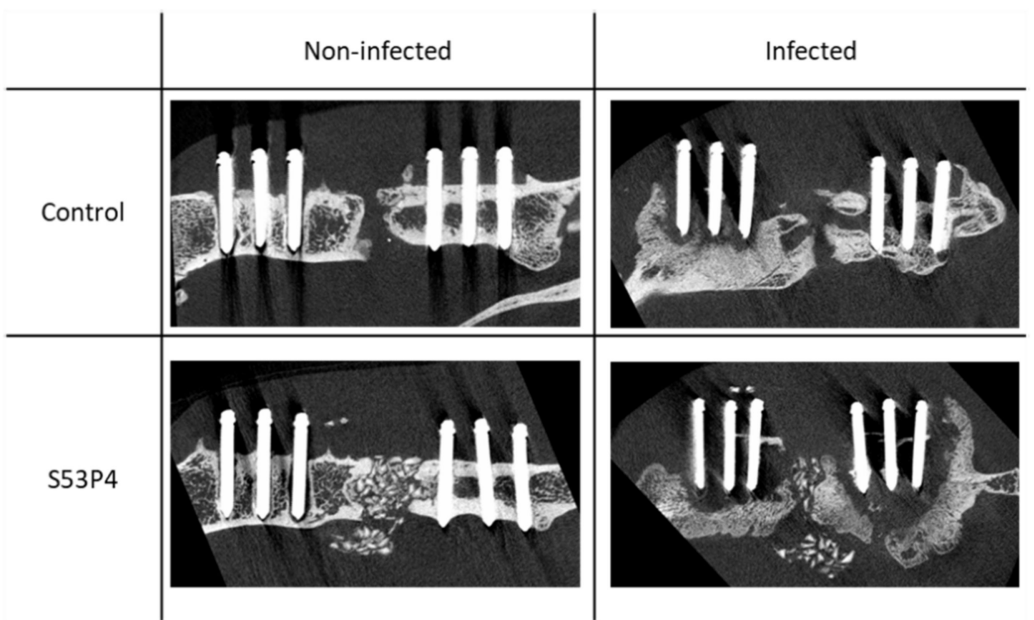

Figure 3. $\mu \mathrm{CT}$ analysis of the bone 4 and 8 weeks after the second surgery. (A) S53P4 led to an increase in bone volume after 4 and 8 weeks in non-infected and infected conditions but performed significantly worse in the infected groups in comparison to the non-infected groups. (B) $\mu \mathrm{CT}$ image coronary slide 8 weeks after the second surgery. ${ }^{* * * *}=p<0.0001 ;{ }^{* *}=p<0.01{ }^{*}=p<0.05$; $+++=p<0.001$, comparison of 4 to 8 weeks; $++=p<0.01$, comparison of 4 to 8 weeks; $+=p<0.05$, comparison of 4 to 8 weeks.

(a)

\section{Bone density (TMD)}

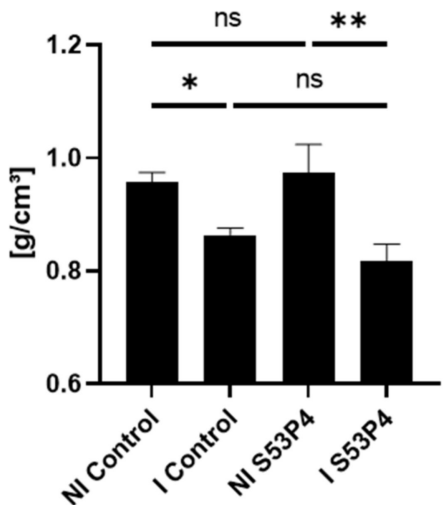

(b)

\section{S53P4 density (BMD)}

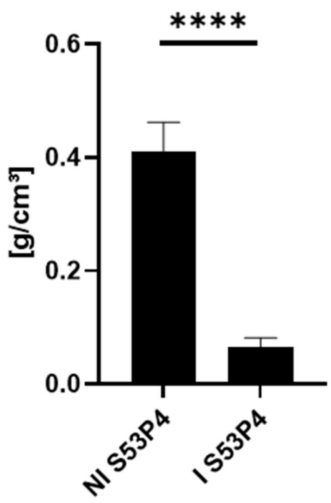

Figure 4. Analysis of bone density (TMD) and the density of S53P4 (BMD). (a) Infected groups showed less density in the control and S53P4 groups. (b) S53P4 density decreased significantly in the infected samples. ${ }^{* * *}=p<0.0001 ;^{* *}=p<0.01 ;^{*}=p<0.05 ;$ ns $=$ not significant. 


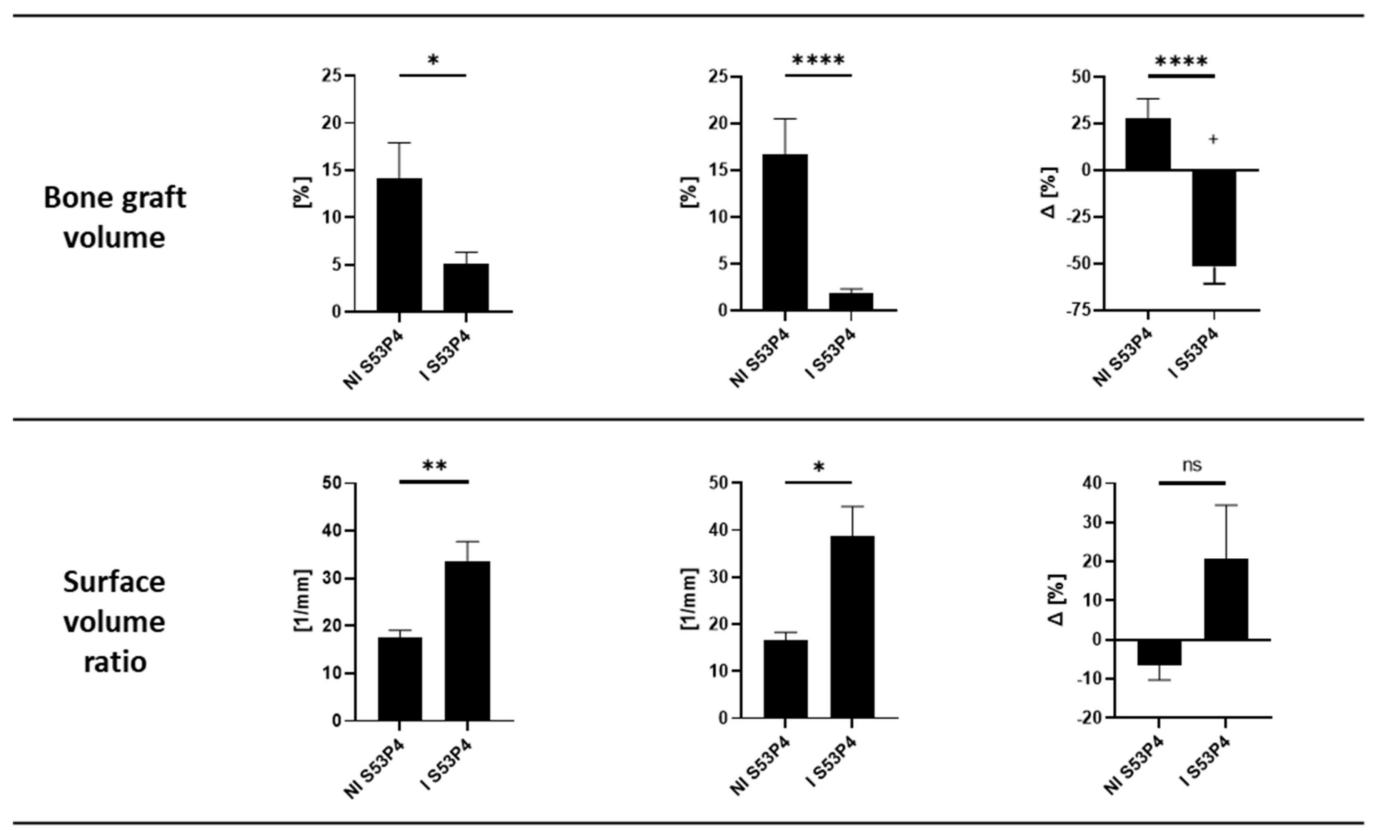

density
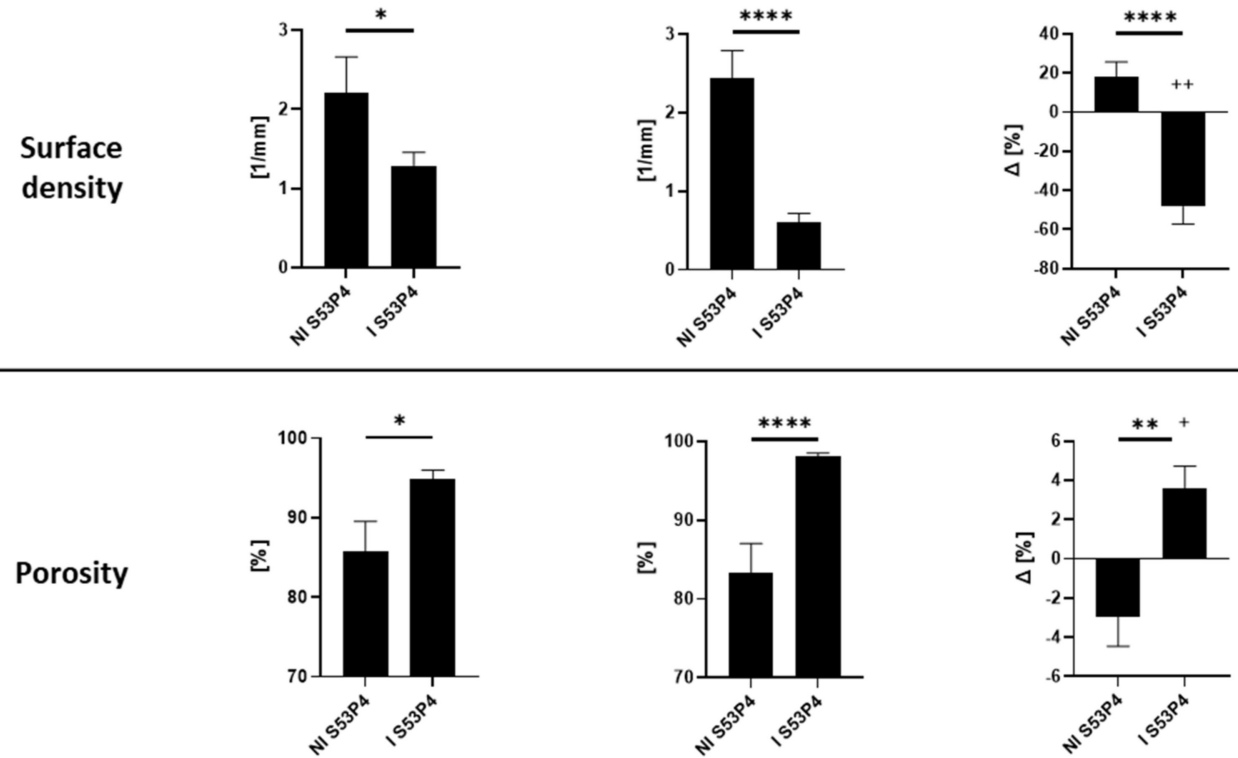

Figure 5. $\mu \mathrm{CT}$ analysis of the bone graft S53P4 4 and 8 weeks after the second surgery. The S53P4 was almost gone in the infected samples, especially 8 weeks after surgery. ${ }^{* * * *}=p<0.0001$; $^{* *}=p<0.01$; * $=p<0.05 ;++=p<0.01 ;+=p<0.05 ;$ ns = not significant.

3.6. There Was a Lower Invasion of Osteoclasts into the Bone Defect in Infected Groups but Also in Non-Infected S53P4

TRAP Staining of the whole femora showed an invasion of osteoclasts at the border between the bone ends and the defect in the NI control. This effect could not be detected in the other groups, indicating an inhibiting effect of either infection and/or S53P4 (Figure 6). 
(a)

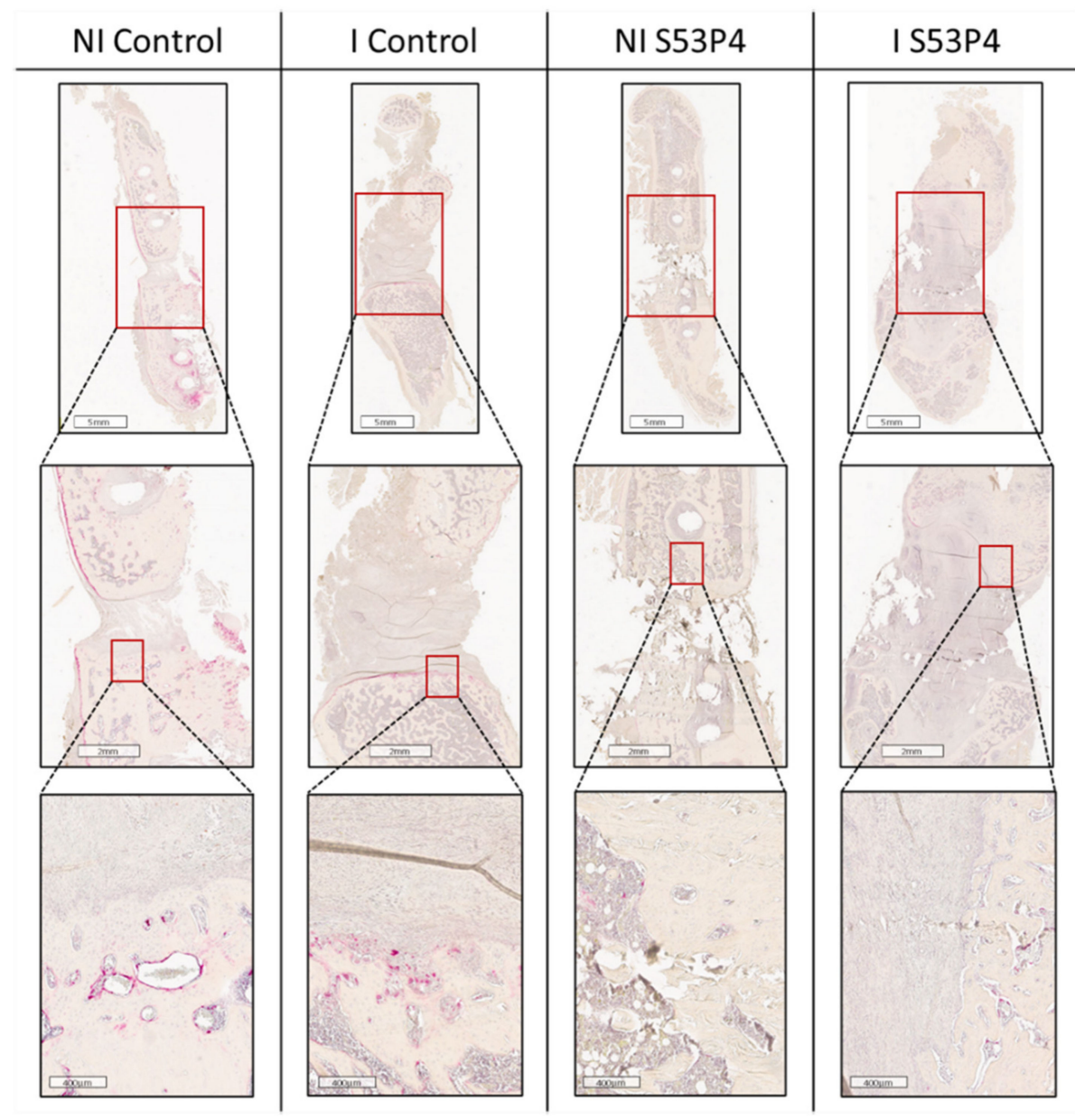

(b)

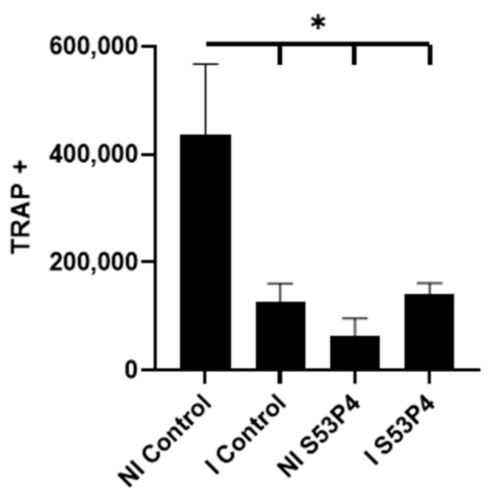

Figure 6. TRAP staining shows invasion of TRAP-positive osteoclasts in the defect in the NI control group but significantly less in the other groups. (a) TRAP staining (osteoclasts with red staining). (b) Quantification. ${ }^{*}=p<0.05$.

\subsection{Infection-Triggered Hypervascularization Was Diminished in I S53P4}

Immunohistochemical analysis comparing the vascularization was performed using the marker CD31. The I control showed significant hypervascularization compared to the NI control. This increase could also be seen in S53P4 but infection-triggered hypervascularization was diminished by roughly $50 \%$ (Figure 7 ). 
(a)

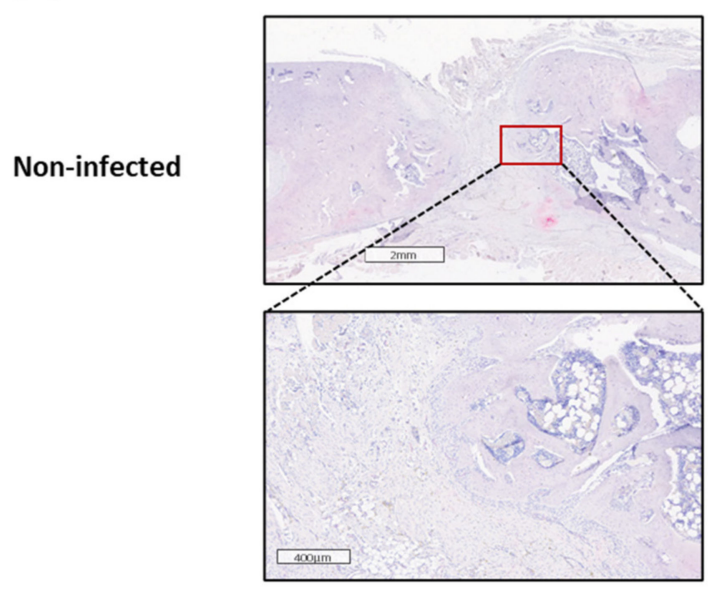

Infected

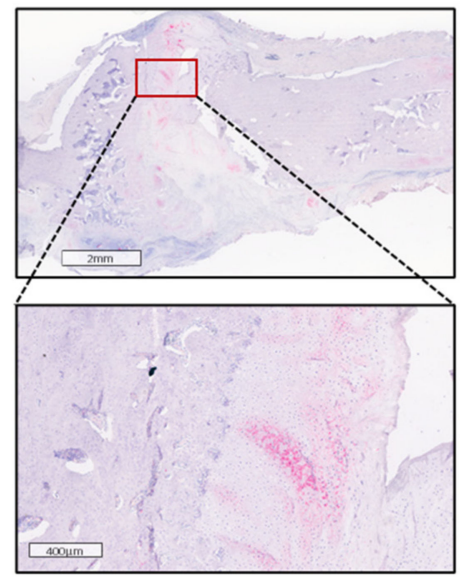

S53P4
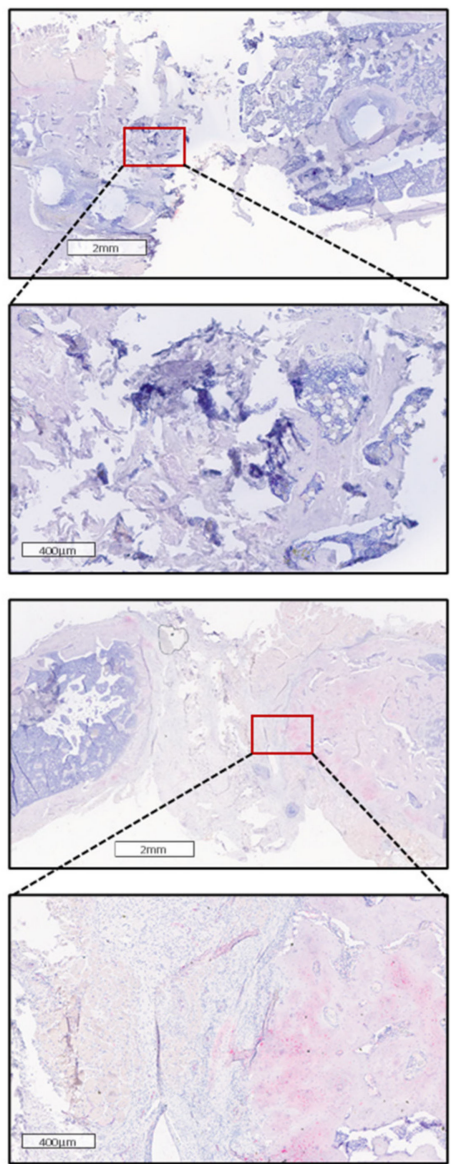

(b)

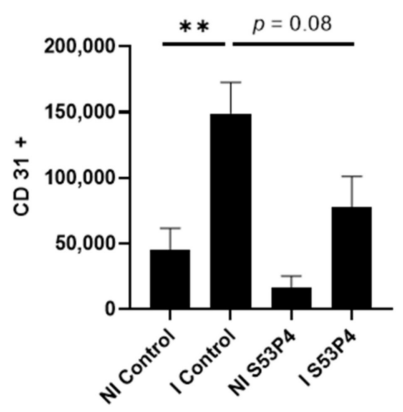

Figure 7. CD31 staining, a marker for vascularization. (a) Comparison of representative parts of the bone defect with magnification of the bone-defect border. Infection led to significant hypervascularization in the control groups. (b) Quantification. ${ }^{* *}=p<0.01$.

\subsection{No Reduction in the Inflammatory Response in S53P4 in CD14 and CD68 Staining}

To analyze the systemic inflammatory response, CD14 and CD68 stainings were prepared. Both CD14 and CD68 are markers for macrophages and correlate with the inflammatory response and the anti-infective potential of the bone graft substitute. In concordance with the results already described in 3.5 , no reduction in inflammatory response was found in S53P4 (Figures 8 and 9). 
(a)

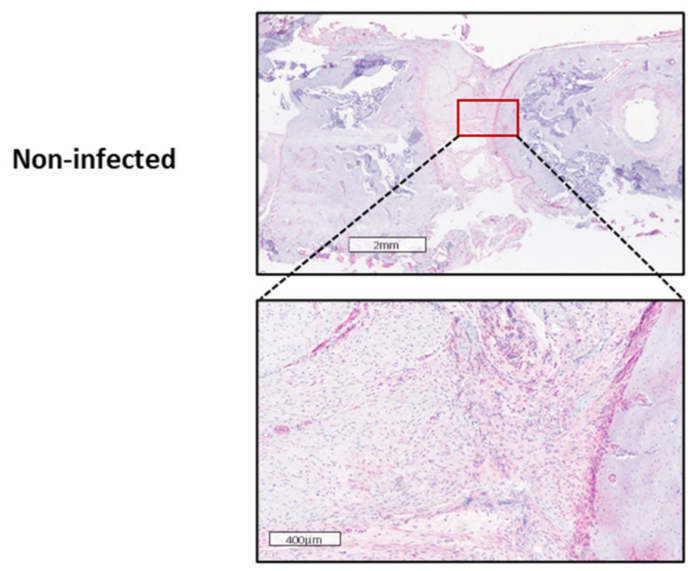

Infected

(b)
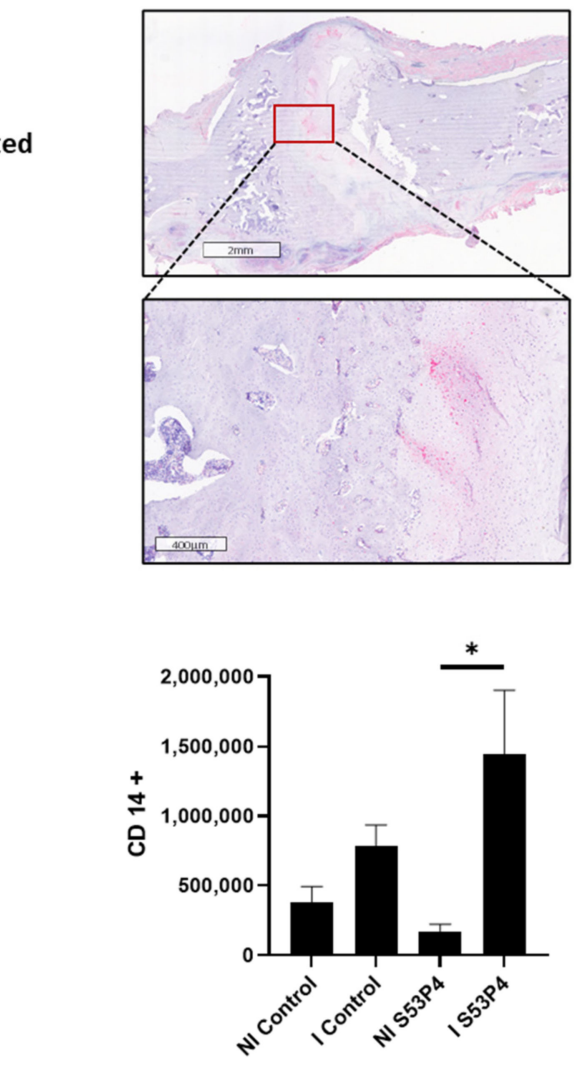

\section{)}
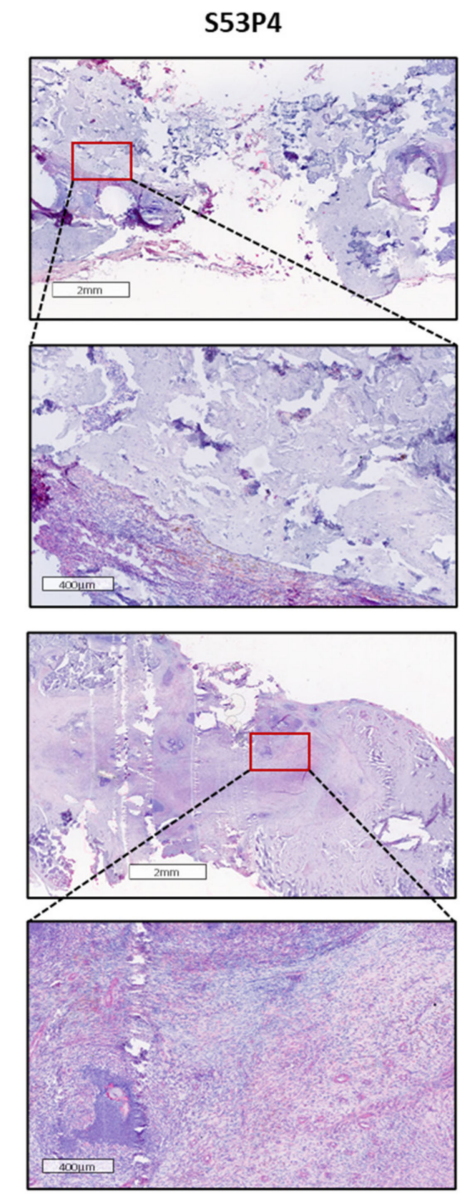

Figure 8. CD14 staining, a marker for macrophages. (a) Comparison of representative parts of the bone defect with magnification of the bone-defect border. There was a significantly increased infiltration of macrophages in I S53P4. (b) Quantification. ${ }^{*}=p<0.05$. 
(a)

Non-infected

Infected

(b)
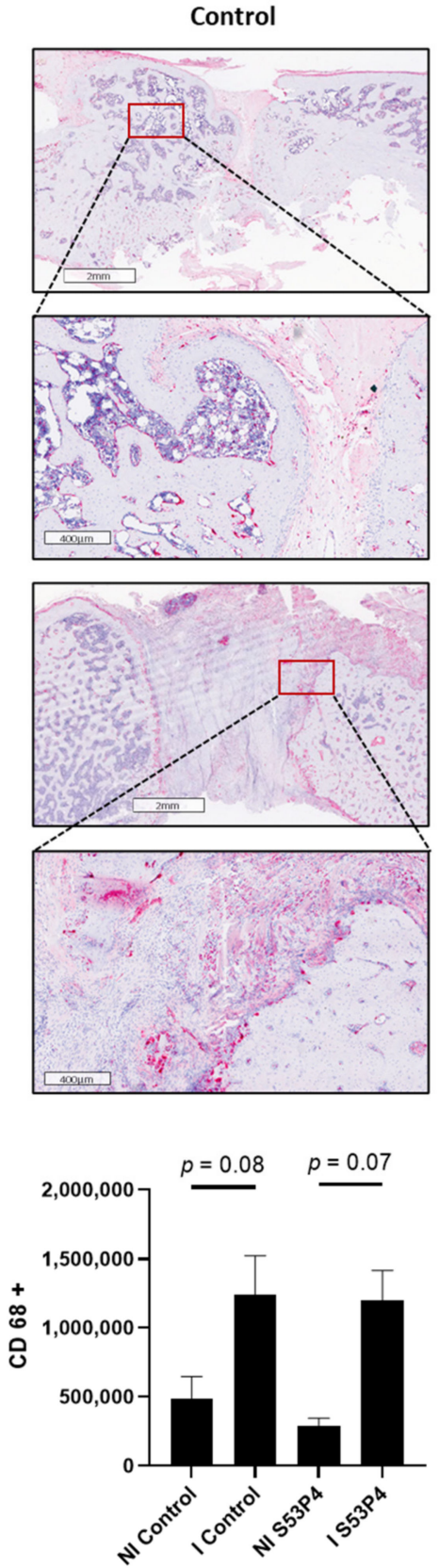

S53P4
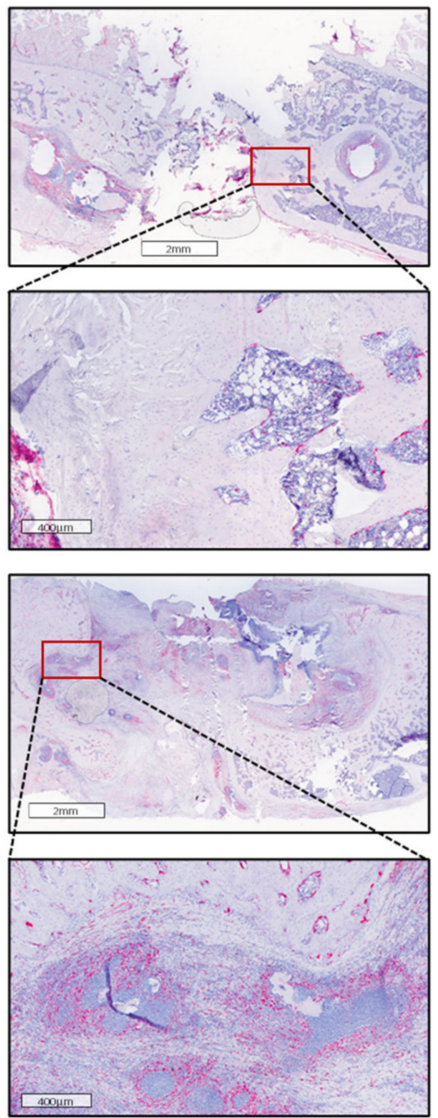

Figure 9. CD68 staining, a marker for macrophages. (a) Comparison of representative parts of the bone defect with magnification of the bone-defect border. There was an increased infiltration of macrophages in I control and I S53P4 without significance. (b) Quantification.

\section{Discussion}

The presented study examined the role of the bioactive glass S53P4 in a sequential non-union animal model [36] under non-infected and infected conditions. Due to the similarities between the two-step model in rats to the approach used to treat non-unions in patients, we were able to test S53P4 in a standardized environment with high translatability into day-to-day clinical work.

We aimed to test the potential of S53P4 for eradicating bacterial infections or keeping non-infected environments aseptic. Furthermore, its potential to induce new bone and, thus, biomechanical stability was examined. In this context osteoconduction and osteoinduction, which are part of the widely recognized diamond concept for healing long bone non-unions, are major aspects addressed in our study [14]. 
Regarding the antiseptic effect of S53P4-although there are widely acknowledged antimicrobial effects of S53P4 in vitro [42,43] - we could not confirm eradication of S. aureus in any of the animals at euthanasia in our microbiologic testing. In addition, bacterial detection increased after the implantation timepoint in both NI groups and it strongly increased in NI S53P4. Thus, our data questioned the role of S53P4 in the treatment of bone infections as well as in the prevention of secondary infections in prior sterile conditions. Of note, is the fact that our microbiological results are based on intraoperative swabs while the gold standard would be the microbiological processing of tissue samples. This could lead to some false negative samples due to lower sensitivity. As we used this method in all our groups, errors between the different conditions could be ruled out. In line with this, staining for markers on immune cells, such as CD14 and CD68, were increased in the infected groups compared to their non-infected counterparts, indicating ongoing osteitis and systemic responses of the immune system. There was no significant reduction with the addition of S53P4, underlining that infection could indeed not be eradicated. This was in line with the results of other groups who also described insufficient eradication by S53P4 [44]. Due to the structure of S53P4, the histological preparation may be impaired due to difficult slicing.

Another important observation was the detrimental effects of the infection on the bone graft S53P4 with a significant reduction in size and a dramatic increase in porosity 4 weeks after surgery, with a significant worsening 8 weeks after surgery, indicating ongoing degradation of S53P4 due to bacterial overload (Figure 5). This effect could not be seen under aseptic conditions, making it unlikely to be due to beneficial cell invasion.

At least in this setting of highly active osteitis, S53P4 could not meet the expectations generated by reports in vitro [31] and in patients [26,45]. One explanation for this discrepancy could be the missing systemic antibiotic therapy in our model, which would have been administered as part of the standard patient treatment [45]. Non-compliancy of the investigated animals could also have affected our results with a mentionable incidence of wound healing disorders. Nevertheless, these results also question the use of S53P4 for implant coatings on metallic implants [46] to prevent secondary infections.

In biomechanical testing, neither the absence nor the presence of S53P4 led to stable unions under non-infected or infected conditions. We would like to mention that stable unions were not part of the expected results as our study primarily focused on analyzing the healing process itself rather than confirming union at the endpoint.

Interestingly $\mu \mathrm{CT}$ scans showed positive effects of S53P4 on the surrounding bone tissue with increased bone volume, indicating an osteoinductive effect of the bone graft substitute, at least under non-infected conditions as seen by other groups $[47,48]$. This early osteoinductive effect of S53P4 could even be detected in infected conditions 4 weeks after the second surgery. It is important to note that there was no further increase in bone volume under infected conditions between 4 and 8 weeks post second surgery, which matched the results of the examination of the bone graft substitute itself where infection led to the degradation of S53P4. Further analysis revealed a decrease in porosity in the bone tissue, which could indicate the induction of sclerotic rather than vital bone tissue. Regarding the osteoconductive potential of S53P4, one could argue that the increased porosity of S53P4 could also appear due to cell invasion. However, TRAP staining showed that although osteoclastic invasion was triggered in the tNI control due to he endogenic repair mechanisms, this activation was diminished under infected conditions but also due to the addition of S53P4. Our results conflicted with the findings in patients, where S53P4 was found to be as good as autologous bone tissue regarding osteointegration [25]. A possible explanation could be the inhibition of osteoclasts by silica, a component of S53P4, which was shown by Van Gestel et al. [49]. Another important difference could be the segmental bone defect used in this study in contrast to the cavitary defects S53P4 that were used in patients, as we know that cavitary defects have different local conditions that potentially facilitate the $\mathrm{pH}$-sensitive antimicrobial effect of S53P4 [19]. 
Sufficient vascularization is one of the major requirements for an effective immune response and the bone healing process [50-52]. Endothelial marker CD31 was increased under infected conditions, indicating infectious hyperemia. Surprisingly, this effect was also seen in I S53P4 animals, but the effect was almost cut in half, indicating a possible inhibition of vascularization due to S53P4. Together with the histological results, this aggravated the impression that S53P4 acted as an inorganic barrier. This trend should lead to further exanimation of vascularization in the use of S53P4 due to its crucial necessity for unions and favorable patient outcomes. Further research is necessary to examine this possible threat.

In the future, the combination of favorable approaches could be of great interest. The combination of the osteoinductive effect of S53P4 and systemic agents, which enhance vascularization and/or osteoconductivity, such as PTH [53] or bisphosphonates, could lead to better outcomes. Another promising approach for the treatment of large bone defects could be the combination of S53P4 with autologous/allogenic bone grafts and local or systemic antibiotics. Newly designed bioactive glasses containing high concentrations of lithium ions [54] or copper-doped glasses [55] could also be interesting materials to study in this context. Their altered properties compared to S53P4 could lead to more osteoconductive or osteoinductive potential. Further research is necessary to address those promising bone graft candidates. Longer observation periods could also show differences in biomechanical stability, which our 8-week period could not show.

\section{Conclusions}

For the first time, S53P4, a bioactive glass already in clinical use, could be investigated in a realistic non-union environment. S53P4 has indicated osteoinductive potential in the treatment of aseptic non-unions. Osteoconduction or biomechanical stability could not be verified on segmental bone defects. Only a minor osteoinduction and osteoconduction was observed in septic non-unions, while the bone substitute was degraded over time. Our results indicated that $\mathrm{S} 53 \mathrm{P} 4$, as a solitary treatment option, was not a promising approach for (infected) non-unions.

Author Contributions: H.F. and J.A. participated in the conceptualization, animal surgeries, methodology, analysis of the findings and drafting of the final manuscript. C.R., N.T. and L.H. participated in the animal surgeries, methodology, analysis of the findings and helped draft the final manuscript. T.G. participated in the conceptualization, analysis of the findings and drafting of the final manuscript. R.S. participated in the biomechanical testing and analysis of the findings. D.N. participated in the microbiological evaluations and analysis of the findings and helped draft the final manuscript as a native speaker. G.S. and P.A.G. helped with conceptualization and supervised the study. All authors have read and agreed to the published version of the manuscript.

Funding: This research was funded by the German Statutory Accident Insurance, a non-profit organization, exclusively (Deutsche Gesetzliche Unfallversicherung (DGUV), Berlin; grant number FR252). In addition, the company Bonalive Biomaterials Ltd. (Turku, Finland) provided the bone substitute for the study. The funding bodies did not participated in the design of the study, the collection, analysis and interpretation of data or the writing of the manuscript.

Institutional Review Board Statement: The study was conducted according to the guidelines of the Declaration of Helsinki and approved by the Animal Experimentation Ethics Committee of the Regierungspräsidium (RP) Karlsruhe; Abteilung 3; Baden-Württemberg; Germany (reference number: 35-9185.81/G-155/17) on 18 December 2017. All animal procedures were performed under the approval and guidance of our RP.

Data Availability Statement: The datasets used and analyzed during the current study are available from the corresponding author on reasonable request.

Acknowledgments: The study team wants to thank the Section of Septic Surgery of the trauma center for their cooperation and support. 
Conflicts of Interest: Thorsten Gühring is a consultant at Bone Support and at Zimmer Biomet and reports personal fees from Bone Support and Zimmer Biomet, outside the submitted work. Holger Freischmidt reports that from 2018 to 2019 the BG Trauma Center Ludwigshafen was a "Center of Excellence" of the Bone support company. The remaining authors confirm that they have no conflicts of interest associated with this publication.

\section{References}

1. Moghaddam, A.; Zietzschmann, S.; Bruckner, T.; Schmidmaier, G. Treatment of atrophic tibia non-unions according to 'diamond concept': Results of one- and two-step treatment. Injury 2015, 46, 39-50. [CrossRef]

2. Lerner, R.K.; Esterhai, J.L., Jr.; Polomano, R.C.; Cheatle, M.D.; Heppenstall, R.B. Quality of life assessment of patients with posttraumatic fracture nonunion, chronic refractory osteomyelitis, and lower-extremity amputation. Clin. Orthop. Relat. Res. 1993, 295, 28-36. [CrossRef]

3. Westgeest, J.; Weber, D.; Dulai, S.K.; Bergman, J.W.; Buckley, R.; Beaupre, L.A. Factors Associated with Development of Nonunion or Delayed Healing after an Open Long Bone Fracture-A Prospective Cohort Study of 736 Subjects. J. Orthop. Trauma 2016, 30, 149-155. [CrossRef] [PubMed]

4. Lerner, R.K.; Esterhai, J.L., Jr.; Polomono, R.C.; Cheatle, M.C.; Heppenstall, R.B.; Brighton, C.T. Psychosocial, functional, and quality of life assessment of patients with posttraumatic fracture nonunion, chronic refractory osteomyelitis, and lower extremity amputation. Arch. Phys. Med. Rehabil. 1991, 72, 122-126.

5. Hak, D.J.; Fitzpatrick, D.; Bishop, J.A.; Marsh, J.L.; Tilp, S.; Schnettler, R.; Simpson, H.; Alt, V. Delayed union and nonunions: Epidemiology, clinical issues, and financial aspects. Injury 2014, 45, S3-S7. [CrossRef]

6. Zura, R.; Mehta, S.; Della Rocca, G.J.; Steen, R.G. Biological Risk Factors for Nonunion of Bone Fracture. JBJS Rev. 2016, 4, S1-S12. [CrossRef]

7. Rupp, M.; Biehl, C.; Budak, M.; Thormann, U.; Heiss, C.; Alt, V. Diaphyseal long bone nonunions-Types, aetiology, economics, and treatment recommendations. Int. Orthop. 2017, 42, 247-258. [CrossRef]

8. Society, C.O.T. Nonunion Following Intramedullary Nailing of the Femur with and without Reaming. J. Bone Jt. Surg. Am. 2003, 85, 2093-2096.

9. Helland, P.; Bøe, A.; Mølster, A.O.; Solheim, E.; Hordvik, M. Open tibial fractures treated with the Ex-fi-re external fixation system. Clin. Orthop. Relat. Res. 1996, 326, 209-220. [CrossRef]

10. Papakostidis, C.; Kanakaris, N.K.; Pretel, J.; Faour, O.; Morell, D.J.; Giannoudis, P.V. Prevalence of complications of open tibial shaft fractures stratified as per the Gustilo-Anderson classification. Injury 2011, 42, 1408-1415. [CrossRef]

11. Teixeira, L.E.M.; Pádua, B.J.; Castilho, A.M.; Araújo, I.D.D.; Andrade, M.A.P.D.; Cardoso, V.N.; Diniz, S.O.; Leal, J.S.; Takenaka, I.K. Influence of biomaterials on scintigraphic diagnosis of periprosthetic infections. Ceftizoxime-99m technetium model. Acta Cir. Bras. 2018, 33, 14-21. [CrossRef]

12. Gustilo, R.B.; Gruninger, R.P.; Davis, T. Classification of type III (severe) open fractures relative to treatment and results Orthopedics 1987, 10, 1781-1788.

13. Schmidt, A.H. Autologous bone graft: Is it still the gold standard? Injury 2021, 52, S18-S22. [CrossRef]

14. Giannoudis, P.V.; Einhorn, T.A.; Marsh, D. Fracture healing: The diamond concept. Injury 2007, 38, S3-S6. [CrossRef]

15. Dimitriou, R.; Mataliotakis, G.I.; Angoules, A.G.; Kanakaris, N.K.; Giannoudis, P.V. Complications following autologous bone graft harvesting from the iliac crest and using the RIA: A systematic review. Injury 2011, 42, S3-S15. [CrossRef]

16. Janicki, P.; Schmidmaier, G. What should be the characteristics of the ideal bone graft substitute? Combining scaffolds with growth factors and/or stem cells. Injury 2011, 42, S77-S81. [CrossRef]

17. Gómez-Barrena, E.; Rosset, P.; Lozano, D.; Stanovici, J.; Ermthaller, C.; Gerbhard, F. Bone fracture healing: Cell therapy in delayed unions and nonunions. Bone 2015, 70, 93-101. [CrossRef]

18. Kurien, T.; Pearson, R.G.; Scammell, B.E. Bone graft substitutes currently available in orthopaedic practice. Bone Jt. J. 2013, 95-B, 583-597. [CrossRef]

19. Jones, J.R. Review of bioactive glass: From Hench to hybrids. Acta Biomater. 2013, 9, 4457-4486. [CrossRef]

20. Hupa, L. Melt-derived bioactive glasses. In Bioactive Glasses; Woodhead Publishing: Cambridge, UK, 2011; pp. 3-28. [CrossRef]

21. Salinas, A.J.; Vallet-Regi, M.; Heikkilä, J. Use of bioactive glasses as bone substitutes in orthopedics and traumatology. In Bioactive Glasses; Woodhead Publishing: Cambridge, UK, 2018; pp. 337-364. [CrossRef]

22. Aurégan, J.C.; Begue, T. Bioactive glass for long bone infection-A systematic review. Injury 2015, 46, 3-7. [CrossRef]

23. Detsch, R.; Stoor, P.; Grünewald, A.; Roether, J.A.; Lindfors, N.C.; Boccaccini, A.R. Increase in VEGF secretion from human fibroblast cells by bioactive glass S53P4 to stimulate angiogenesis in bone. J. Biomed. Mater. Res. Part A 2014, 102, 4055-4061. [CrossRef]

24. Rahaman, M.N.; Day, D.E.; Sonny Bal, B.; Fu, Q.; Jung, S.B.; Bonewald, L.F.; Tomsia, A.P. Bioactive glass in tissue engineering. Acta Biomater. 2011, 7, 2355-2373. [CrossRef]

25. Lindfors, N.C.; Heikkilä, J.T.; Koski, I.; Mattila, K.; Aho, A.J. Bioactive glass and autogenous bone as bone graft substitutes in benign bone tumors. J. Biomed. Mater. Res. Part B Appl. Biomater. 2008, 90B, 131-136. [CrossRef]

26. van Gestel, N.A.P.; Geurts, J.; Hulsen, D.J.W.; van Rietbergen, B.; Hofmann, S.; Arts, J.J. Clinical Applications of S53P4 Bioactive Glass in Bone Healing and Osteomyelitic Treatment: A Literature Review. BioMed Res. Int. 2015, 2015, 684826. [CrossRef] 
27. Westhauser, F.; Weis, C.; Prokscha, M.; Bittrich, L.A.; Li, W.; Xiao, K.; Kneser, U.; Kauczor, H.-U.; Schmidmaier, G.; Boccaccini, A.R.; et al. Three-dimensional polymer coated 45S5-type bioactive glass scaffolds seeded with human mesenchymal stem cells show bone formation in vivo. J. Mater. Sci. Mater. Med. 2016, 27, 119. [CrossRef]

28. Morgenstern, M.; Vallejo, A.; McNally, M.A.; Moriarty, T.F.; Ferguson, J.Y.; Nijs, S.; Metsemakers, W.J. The effect of local antibiotic prophylaxis when treating open limb fractures: A systematic review and meta-analysis. Bone Jt. Res. 2018, 7, 447-456. [CrossRef]

29. Solberg, B.D.; Gutow, A.; Baumgaertner, M.R. Efficacy of Gentamycin-Impregnated Resorbable Hydroxyapatite Cement in Treating Osteomyelitis in a Rat Model. J. Orthop. Trauma 1999, 13, 102-106. [CrossRef]

30. Stravinskas, M.; Nilsson, M.; Horstmann, P.; Petersen, M.M.; Tarasevicius, S.; Lidgren, L. Antibiotic Containing Bone Substitute in Major Hip Surgery: A Long Term Gentamicin Elution Study. J. Bone Jt. Infect. 2018, 3, 68-72. [CrossRef]

31. Stoor, P.; Söderling, E.; Salonen, J.I. Antibacterial effects of a bioactive glass paste on oral microorganisms. Acta Odontol. Scand. 1998, 56, 161-165. [CrossRef] [PubMed]

32. Zhang, D.; Leppäranta, O.; Munukka, E.; Ylänen, H.; Viljanen, M.K.; Eerola, E.; Hupa, M.; Hupa, L. Antibacterial effects and dissolution behavior of six bioactive glasses. J. Biomed. Mater. Res. Part A 2010, 93A, 475-483. [CrossRef]

33. Zhang, D.; Munukka, E.; Leppäranta, O.; Hupa, L.; Ylänen, H.O.; Salonen, J.I.; Eerola, E.; Viljanen, M.K.; Hupa, M. Comparison of Antibacterial Effect of Three Bioactive Glasses. Key Eng. Mater. 2006, 309-311, 345-348. [CrossRef]

34. Bortolin, M.; De Vecchi, E.; Romanò, C.L.; Toscano, M.; Mattina, R.; Drago, L. Antibiofilm agents against MDR bacterial strains: Is bioactive glass BAG-S53P4 also effective? J. Antimicrob. Chemother. 2016, 71, 123-127. [CrossRef] [PubMed]

35. Tanner, M.C.; Heller, R.; Westhauser, F.; Miska, M.; Ferbert, T.; Fischer, C.; Gantz, S.; Schmidmaier, G.; Haubruck, P. Evaluation of the clinical effectiveness of bioactive glass (S53P4) in the treatment of non-unions of the tibia and femur- study protocol of a randomized controlled non-inferiority trial. Trials 2018, 19, 299. [CrossRef] [PubMed]

36. Helbig, L.; Guehring, T.; Titze, N.; Nurjadi, D.; Sonntag, R.; Armbruster, J.; Wildemann, B.; Schmidmaier, G.; Gruetzner, A.P.; Freischmidt, H. A new sequential animal model for infection-related non-unions with segmental bone defect. BMC Musculoskelet. Disord. 2020, 21, 329. [CrossRef]

37. Lucke, M.; Wildemann, B.; Sadoni, S.; Surke, C.; Schiller, R.; Stemberger, A.; Raschke, M.; Haas, N.P.; Schmidmaier, G. Systemic versus local application of gentamicin in prophylaxis of implant-related osteomyelitis in a rat model. Bone 2005, 36, 770-778. [CrossRef]

38. Helbig, L.; Guehring, T.; Rosenberger, S.; Ivanova, A.; Kaeppler, K.; Fischer, C.A.; Moghaddam, A.; Schmidmaier, G. A new animal model for delayed osseous union secondary to osteitis. BMC Musculoskelet. Disord. 2015, 16, 362. [CrossRef]

39. Lane, J.M.; Sandhu, H.S. Current approaches to experimental bone grafting. Orthop. Clin. N. Am. 1987, 18, 213-225. [CrossRef]

40. An, Y.H.; Friedman, R.J. Animal models of orthopedic implant infection. J. Invest. Surg. 1998, 11, 139-146. [CrossRef]

41. Nurjadi, D.; Friedrich-Janicke, B.; Schafer, J.; Van Genderen, P.J.; Goorhuis, A.; Perignon, A.; Neumayr, A.; Mueller, A.; Kantele, A.; Schunk, M.; et al. Skin and soft tissue infections in intercontinental travellers and the import of multi-resistant Staphylococcus aureus to Europe. Clin. Microbiol. Infect. 2015, 21, 567.e1-567.e10. [CrossRef]

42. Gronseth, T.; Vestby, L.K.; Nesse, L.L.; von Unge, M.; Silvola, J.T. Bioactive glass S53P4 eradicates Staphylococcus aureus in biofilm/planktonic states in vitro. Ups. J. Med. Sci. 2020, 125, 217-225. [CrossRef]

43. Van Vugt, T.A.G.; Heidotting, J.; Arts, J.J.; Ploegmakers, J.J.W.; Jutte, P.C.; Geurts, J.A.P. Mid-term clinical results of chronic cavitary long bone osteomyelitis treatment using S53P4 bioactive glass: A multi-center study. J. Bone Jt. Infect. 2021, 6, 413-421. [CrossRef]

44. Thijssen, E.G.J.; van Gestel, N.A.P.; Bevers, R.; Hofmann, S.; Geurts, J.; van Loo, I.H.M.; Arts, J.J. Assessment of Growth Reduction of Five Clinical Pathogens by Injectable S53P4 Bioactive Glass Material Formulations. Front. Bioeng. Biotechnol. 2020 8, 634. [CrossRef]

45. Gaiarsa, G.P.; Dos Reis, P.R.; Kojima, K.E.; Silva, J.S.; Lima, A. A Retrospective Case-Series on the Use of S53p4 Bioactive Glass for the Adjunctive Treatment of Septic Diaphyseal Non-Union. Acta Ortop. Bras. 2019, 27, 273-275. [CrossRef]

46. Brunello, G.; Elsayed, H.; Biasetto, L. Bioactive Glass and Silicate-Based Ceramic Coatings on Metallic Implants: Open Challenge or Outdated Topic? Materials 2019, 12, 2929. [CrossRef]

47. Bjorkenheim, R.; Jamsen, E.; Eriksson, E.; Uppstu, P.; Aalto-Setala, L.; Hupa, L.; Eklund, K.K.; Ainola, M.; Lindfors, N.C.; Pajarinen, J. Sintered S53P4 bioactive glass scaffolds have anti-inflammatory properties and stimulate osteogenesis in vitro. Eur. Cells Mater. 2021, 41, 15-30. [CrossRef]

48. Eriksson, E.; Bjorkenheim, R.; Stromberg, G.; Ainola, M.; Uppstu, P.; Aalto-Setala, L.; Leino, V.M.; Hupa, L.; Pajarinen, J.; Lindfors, N.C. S53P4 bioactive glass scaffolds induce BMP expression and integrative bone formation in a critical-sized diaphysis defect treated with a single-staged induced membrane technique. Acta Biomater. 2021, 126, 463-476. [CrossRef]

49. van Gestel, N.A.P.; Schuiringa, G.H.; Hennissen, J.; Delsing, A.C.A.; Ito, K.; van Rietbergen, B.; Arts, J.J.; Hofmann, S. Resorption of the calcium phosphate layer on S53P4 bioactive glass by osteoclasts. J. Mater. Sci. Mater. Med. 2019, 30, 94. [CrossRef]

50. Beamer, B.; Hettrich, C.; Lane, J. Vascular endothelial growth factor: An essential component of angiogenesis and fracture healing. HSS J. 2010, 6, 85-94. [CrossRef]

51. Hausman, M.R.; Schaffler, M.B.; Majeska, R.J. Prevention of fracture healing in rats by an inhibitor of angiogenesis. Bone 2001, 29, 560-564. [CrossRef]

52. Song, E.; Mao, T.; Dong, H.; Boisserand, L.S.B.; Antila, S.; Bosenberg, M.; Alitalo, K.; Thomas, J.L.; Iwasaki, A. VEGF-C-driven lymphatic drainage enables immunosurveillance of brain tumours. Nature 2020,577, 689-694. [CrossRef] 
53. Freischmidt, H.; Armbruster, J.; Bonner, E.; Guehring, T.; Nurjadi, D.; Bechberger, M.; Sonntag, R.; Schmidmaier, G.; Grutzner, P.A.; Helbig, L. Systemic Administration of PTH Supports Vascularization in Segmental Bone Defects Filled with Ceramic-Based Bone Graft Substitute. Cells 2021, 10, 2058. [CrossRef] [PubMed]

54. Boora, M.; Malik, S.; Kumar, V.; Bala, M.; Arora, S.; Rohilla, S.; Kumar, A.; Dalal, J. Investigation of structural and impedance spectroscopic properties of borate glasses with high Li+ concentration. Solid State Ion. 2021, 368, 115704. [CrossRef]

55. Westhauser, F.; Decker, S.; Nawaz, Q.; Rehder, F.; Wilkesmann, S.; Moghaddam, A.; Kunisch, E.; Boccaccini, A.R. Impact of Zinc- or Copper-Doped Mesoporous Bioactive Glass Nanoparticles on the Osteogenic Differentiation and Matrix Formation of Mesenchymal Stromal Cells. Materials 2021, 14, 1864. [CrossRef] [PubMed] 